\title{
Erratum
}

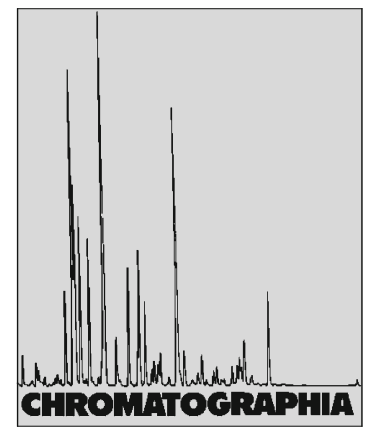

2009, 69, 1141

\section{Simultaneous LC-MS-MS Analysis of Valsartan and Hydrochlorothiazide in Human Plasma}

Hiten Janardan Shah ${ }^{1,2, 凶}$, Naresh B. Kataria ${ }^{1}$, Gunta Subbaiah ${ }^{1}$, Chhagan N. Patel ${ }^{1}$

${ }^{1}$ Bioanalytical Laboratory, Torrent Research Center, Gandhinagar 382428, Gujarat, India;

E-Mail: hitenshah@torrentpharma.com; hiten12345@hotmail.com

2 Shri Sarvajanik Pharmacy College, Mehsana 384001, Gujarat, India

\section{Erratum to: Chromatographia (2009) 69:1055-1060 DOI 10.1365/s10337-009-0950-1}

Unfortunately, the last author's name (C.N.P.) was spelled incorrectly. The correct name is Chhagan N. Patel. 